\title{
Biopolítica e Neoliberalismo: A Vigilância Sanitária no \\ LIMITE DA UTILIDADE PARA O COMÉRCIO INTERNACIONAL
}

\author{
BIOPOLITICS AND NEOLIBERALISM: HEALTH SURVEILLANCE AT THE \\ LIMITS OF ITS UTILITY FOR THE INTERNATIONAL TRADE
}

Renata Campos Motta ${ }^{(*)}$

\section{RESUMO}

Esta pesquisa parte da problemática das relações entre saúde e comércio internacional para analisar como a Reforma do Estado brasileira em vigilância sanitária na década de 1990, notadamente, a criação da Agência Nacional de Vigilância Sanitária (Anvisa) está relacionada com o avanço do regime multilateral de comércio. Com base na reflexão de Foucault sobre o neoliberalismo, analisou-se como as questões neoliberais de "como" e "até que limite é útil" a intervenção estatal na economia informaram as demandas tanto do mercado internacional como do doméstico sobre as características do desenho institucional adotado.

\section{Palavras-chave}

Agências Reguladoras; Comércio Internacional; Organização Mundial do Comércio; Vigilância Sanitária.

\section{ABSTRACT}

Taking into consideration the relationships between health and international trade throughout the 90's, this paper analyzes the ways in which the Brazilian State Reform, in the health surveillance sector, specifically, the cre-

(*) Mestranda em Ciências Sociais, na Universidade de Brasília (UnB), Especialista em Saúde Internacional pela Faculdade de Saúde Pública da Universidade de São Paulo (FSP-USP), Especialista em Regulação e Vigilância pela Agência Nacional de Vigilância Sanitária (ANVISA). E-mail $<$ renatacmotta@gmail.com>. Recebido em 31.3.08. Aprovado em 3.5.08. 
ation of the National Health Surveillance Agency (Anvisa) is related to the advance of the multilateral trade regime. Considering Foucault's reflexions on neoliberalism, this work analyses how the neoliberal questions of "how" and "until what limit it is useful" the state intervention in the economy have informed both international and domestic markets demands about the characteristics of adopted the institutional design.

\section{Keywords}

Health Surveillance; International Trade; Regulatory Agencies; World Trade Organization.

\section{INTRODUÇÃO}

O tema deste artigo insere-se dentro da problemática das relações entre saúde e comércio internacional. Seu recorte são as relações entre os avanços no regime multilateral de comércio e as transformações no modo de atuação estatal na área de vigilância sanitária nos anos de 1990, dentro do contexto da Reforma do Estado brasileira. Mais especificamente, o objeto de estudo é a nova forma de exercício do poder estatal no campo da vigilância sanitária a partir do advento das agências reguladoras no arranjo institucional brasileiro, notadamente, da criação da Agência Nacional de Vigilância Sanitária (Anvisa) e sua relação com os debates sobre as questões sanitárias na agenda de liberalização comercial multilateral.

Agências reguladoras são entendidas aqui como um modelo institucional de órgão público caracterizado pela função de regulação e por uma relação de autonomia especial com os Poderes Executivo, Legislativo e Judiciário ${ }^{(1)}$. Por sua vez, vigilância sanitária é um campo específico dentro das políticas públicas de saúde. Enquanto o objetivo destas, no geral, é amparar a população dos riscos sociais clássicos relativos à doença, o objeto da vigilância sanitária são os riscos sanitários advindos do consumo de bens e serviços $^{(2)}$.

(1) MARQUES NETO, Floriano de Azevedo. Agências reguladoras independentes: fundamentos e seu regime jurídico. Belo Horizonte: Fórum, 2005.

(2) A Lei n. 8.080, de 19 de setembro de 1990, define em seu artigo 6o, inciso XI, § 1: "Entende-se por vigilância sanitária um conjunto de ações capaz de eliminar, diminuir ou prevenir riscos à saúde e de intervir nos problemas sanitários decorrentes do meio ambiente, da produção e circulação de bens e da prestação de serviços de interesse da saúde, abrangendo: I — o controle de bens de consumo que, direta ou indiretamente, se relacionem com a saúde, compreendidas todas as etapas e processos, da produção ao consumo; e II — o controle da prestação de serviços que se relacionam direta ou indiretamente com a saúde (BRASIL, 1990). 
Pretende-se analisar como a opção por este modelo institucional no Brasil, para a reforma do Estado em vigilância sanitária, está relacionada ao avanço do livre comércio na década de noventa. Isto será feito a partir da reflexão sobre o neoliberalismo levada a cabo por Michel Foucault( ${ }^{(3)}$ em seu curso "Naissance de la Biopolitique" e pela análise do tratamento do tema saúde no regime ${ }^{(4)}$ multilateral de comércio. O argumento que será desenvolvido mostra que a criação da Anvisa vai ao encontro da demanda neoliberal por um marco institucional forte, como uma das condições para a eficiência do mercado, e da demanda dos acordos assinados pelo Brasil, no âmbito da Organização Mundial do Comércio (OMC), por uma institucionalidade baseada no conhecimento e insulada de considerações políticas.

A proposta é desenvolver, para o âmbito da vigilância sanitária, o argumento de que as agências reguladoras foram criadas em um período de predominância do ideário neoliberal iconizado pelas privatizações no setor de infra-estrutura. O caráter inovador que se pretende nesta pesquisa é discutir este entendimento, que associa regulação, privatizações e retirada do Estado da economia (conhecido como Estado mínimo), argumentando que, no campo da vigilância sanitária, essa transformação no modo de atuação estatal de acordo com a utilidade para o mercado internacional, longe de significar uma retirada do Estado do setor, aumentou e redefiniu os contornos de sua intervenção.

A primeira parte trata da argumentação de Foucault sobre duas lógicas de justificação da intervenção estatal, o direito e o utilitarismo; a análise desta última culminado na reflexão do autor sobre o neoliberalismo e sua concepção do papel do Estado na economia. A segunda parte aborda a inserção do tema 'saúde' na agenda do regime multilateral de comércio, a partir do momento em que aquela é interpretada como uma possível barreira ao comércio internacional e, portanto, este regime passa a disciplinar o modo como os Estados protegem a saúde de sua população. Estas obrigações assumidas pelos países no âmbito do regime multilateral de comércio criam, no entanto, uma demanda por um marco institucional capaz de cumpri-las. Utilizando o instrumental teórico de Foucault, essa demanda leva à questão neoliberal do "como intervir?", a qual será tratada na última parte, sobre a Reforma do Estado brasileiro da década de noventa e a opção pelo modelo de agência reguladora para a reforma no setor de vigilância sanitária, sendo que este modelo institucional foi considerado o modo de intervenção estatal mais apto para atender às exigências pelas correções das falhas de mercado no setor, bem como àquelas da liberalização comercial.

(3) FOUCAULT, Michel. Naissance de la biopolitique. Cours au Collège de France. Ed. Seuil: Gallimard, 2004.

(4) Krasner (1983, p. 1) define regimes internacionais como "princípios, normas, regras e procedimentos de tomada de decisões em torno dos quais as expectativas dos atores convergem em um determinado tema" (tradução livre). 
Após esses passos, apontaremos algumas considerações sobre as relações possíveis entre saúde e comércio internacional na Reforma do Estado brasileiro no setor de vigilância sanitária. O argumento principal da pesquisa é de que, partindo de um possível conflito entre os dois termos quando a saúde é interpretada como barreira ao comércio internacional, há uma progressiva mitigação da autonomia do campo sanitário, na medida em que a intervenção estatal em vigilância sanitária passa a ser disciplinada pelas regras do regime multilateral de comércio. A criação de uma agência reguladora para o setor no Brasil, com suas características de especialização técnica e independência política, foi ao encontro desta definição neoliberal de como e até que limite é útil a intervenção do Estado na economia.

\section{A PERSPECTIVA NEOLIBERAL: A INTERVENÇÃO DO ESTADO NO LIMITE DA UTILIDADE PARA O MERCADO}

A análise que se pretende fazer sobre as transformações no modo de atuação estatal no campo da vigilância sanitária representada pela adoção do modelo de agências reguladoras no Brasil foi inspirada na reflexão levada a cabo por Michel Foucault em seu curso "Naissance de la Biopolitique" sobre a história da prática governamental no Ocidente. Embora, à primeira vista, pareça que o objeto deste curso de Foucault no College de France tenha sido a biopolítica, que o filósofo caracteriza como as questões deparadas pelo Estado com relação a sua população, o curso teve como foco o neoliberalismo. A justificativa do autor para tanto é a necessidade de se compreender o regime de veridição da razão governamental, ou seja, "o conjunto de regras que permitem, a respeito de um discurso dado, fixar quais são os enunciados que podem ser caracterizados como verdadeiros ou falsos"(5). Segundo o autor, a prática governamental passa a ser julgada como certa ou errada a partir da economia, daí o estudo do neoliberalismo.

Este seria uma reformulação da idéia corrente do liberalismo da nãointervenção do Estado na economia para a definição de critérios da utilidade e do modo de o Estado intervir em um certo domínio econômico. Foucault apresenta a questão do liberalismo como a questão da frugalidade do governo, que ele considera fundamental para a reflexão política, a partir do final do século XVIII, passando por todo o século XIX, e que se mantém atual nos dias de hoje. A frugalidade do governo surge em um momento em que a intervenção do Estado na sociedade se intensifica - o que poderia parecer um paradoxo, mas que, pelo contrário, se explica pelo próprio fato de a maior participação do Estado no cotidiano dos indivíduos vir acompanhada pela

(5) FOUCAULT, Michel, op. cit., p. 37, tradução livre. 
contínua reflexão sobre os limites dessa atuação. Em outras palavras, o Estado "não deixou de ser perseguido, tanto do exterior como do interior, pela questão do demasiado e do insuficiente"(6).

A razão de Estado predominante até então, que tinha como objetivo garantir o crescimento de sua força, riqueza e poder, é redefinida como "razão do menor Estado" (raison du moindre État). Se a razão de Estado tinha apenas como limitação o exterior — ou seja, os outros Estados europeus, que se organizavam a partir do princípio da balança de poder —, pode-se falar em "razão do menor Estado" quando, além desta limitação exterior, ela apresenta também uma limitação interior que, até então, não estava presente no Estado de polícia característico do período absolutista. Esta limitação deriva da economia política, a partir da transformação do papel do mercado como lugar de jurisdição para incluir também o papel de lugar de veridição.

Na Idade Média, o mercado havia funcionado como um lugar de jurisdição na medida em que havia regras estritas para assegurar, por um lado, a proteção do comprador com relação às possibilidades de fraude dos produtos e, por outro, a justiça distributiva do preço, "isto é, um preço que deve manter uma certa relação com o trabalho realizado, com as necessidades dos mercadores, com as necessidades, certamente, e as possibilidades dos consumidores"(7). A partir da metade do século XVIII, o mercado se torna também um espaço de veridição no sentido de se constituir no lugar onde mecanismos naturais e espontâneos formam um preço natural, revelando uma verdade. A economia política torna-se, portanto, um regime de veridição. A conseqüência é que, se as regras de mercado definem um preço que é considerado o único verdadeiro, qualquer intervenção nos mecanismos de livre mercado levaria a uma distorção da verdade; portanto, o Estado há de respeitar este lugar da verdade. Trata-se de uma limitação que nasce do interior do Estado, de seu mercado interno, que the demanda sua autolimitação( ${ }^{(8)}$.

O problema que surge, neste momento, é como formular esta limitação em termos jurídicos, ou seja, como o governo irá formular o respeito à verdade estabelecida pelo mercado em termos de lei a respeitar. Há, portanto, o que Foucault chama de "deslocamento do centro de gravidade do direito público", que substitui a problemática das fontes do poder e da legitimidade do soberano por aquela dos limites jurídicos ao exercício do poder público. Duas vias principais foram levantadas para elaborar uma resposta a este

(6) FOUCAULT, Michel, op. cit., p. 30, tradução livre.

(7) Id. Ibid., p. 32, tradução livre.

(8) É o mercado que fará com que o governo, a partir de agora, para poder ser um bom governo, deva funcionar de acordo com a verdade. [...] A economia política tem sido, inclusive em sua formulação teórica, qualquer coisa de importante na medida em que ela indica onde o governo deve ir encontrar o princípio de verdade de sua própria prática governamental" (FOUCAULT, 2004, p. 34, tradução livre). 
problema: a via axiomática ou jurídico-dedutiva, e a via indutiva-residual. A primeira tem como ponto de partida os direitos naturais do indivíduo: a partir da determinação daqueles que são imprescritíveis, podem-se deduzir quais seriam passíveis de serem cedidos ao soberano. Os direitos naturais são, desta forma, fundamento do poder público, ao mesmo tempo em que sua limitação. A segunda via parte da prática governamental, analisando-a em função de seus limites desejáveis. Trata-se da via radical utilitarista; o termo "radical" entendido no sentido do radicalismo inglês, que consiste em sempre questionar a utilidade ou a não utilidade do governo( ${ }^{(9)}$.

Foucault afirma que ambas não são excludentes - antes, sua coexistência marca a ambigüidade do liberalismo europeu. Todavia, é a via utilitarista que vai mais fortemente caracterizar não só o liberalismo europeu, mas, segundo o autor, a própria história do poder público no Ocidente. "E, portanto, é bem esse problema da utilidade, da utilidade individual e coletiva, da utilidade de cada um e de todos, da utilidade dos indivíduos e da utilidade geral, é esse problema que vai ser enfim o grande critério de elaboração dos limites do poder público [...]."(10)

Como critério de utilidade, Foucault introduz a categoria do interesse. Se antes o interesse ao qual servia a razão de Estado era definido tendo como referência o próprio Estado (sua força, sua riqueza, seu poder), na nova forma de governar - que tem como fundamentos e limitações a veridição do mercado e o princípio da utilidade - o interesse que a razão do menor Estado deve obedecer passa a ser, agora, "no plural", interesses: "[...] é um jogo complexo entre os interesses individuais e coletivos, a utilidade social e o lucro econômico, entre o regime do poder público e o equilíbrio de mercado, [...] entre os direitos fundamentais e a independência dos governados."(11) Quando a intervenção do Estado deixa de ser legítima em termos de direito e o soberano deixa de ser soberano sobre os indivíduos e suas coisas, o interesse se torna a superfície de intervenção do Estado em sua jurisdição. A questão fundamental do liberalismo é, para o autor, qual o valor de utilidade das ações governamentais em uma sociedade na qual é a troca que define o valor das coisas (FOUCAULT, 2004: p. 48).

Após analisar o liberalismo clássico, Foucault parte para a análise do neoliberalismo. Este é, segundo o autor, produto de certas transformações no liberalismo clássico. Há uma transformação na própria questão com que cada qual se ocupa: o problema que surge para o neoliberalismo não é mais

(9) O limite da competência do governo será definido pelas fronteiras da utilidade de uma intervenção governamental. Colocar a um governo, a cada instante, a cada momento de sua ação, a propósito de cada uma de suas instituições, antigas ou recentes, a questão: isso é útil, a quem isso é útil, dentro de que limites isso é útil, a partir do que isso se torna inútil, a partir de que isso se torna nocivo? (FOUCAULT, Michel, op. cit., p. 42, tradução livre).

(10) FOUCAULT, Michel, op. cit., p. 45, tradução livre.

(11) FOUCAULT, Michel, op. cit., p. 46, tradução livre. 
aquele do liberalismo do século XVIII, a saber, a de separar, dentro de uma sociedade política dada, um espaço livre para o mercado, no qual o governo não intervirá (laissez-faire). O problema para o neoliberalismo é de "[...] como se pode regular o exercício global do poder político de acordo com os princípios de uma economia de mercado."(12)

Em decorrência, há uma dissociação entre o princípio econômico do mercado e o princípio político do laissez-faire. Isso porque os teóricos neoliberais apresentam uma teoria da concorrência pura que, partindo da constatação de sua fragilidade em termos de existência histórica, deixam de considerá-la como algo dado e natural e, portanto, passam a identificar a necessidade de uma política (isto é, uma intervenção do Estado) que assegure o espaço real no qual a estrutura formal da concorrência pura possa agir livremente para a formação dos preços. "Uma economia de mercado sem laissez-faire, isto é, uma política ativa sem dirigismo. O neoliberalismo não se coloca sob o signo do laissez-faire, mas, ao contrário, sob o signo de uma vigilância, de uma atividade, de uma intervenção permanente."(13)

Pode-se dizer que a questão da utilidade da intervenção governamental se transforma da definição entre intervir e não intervir para a definição de como intervir, a partir do momento em que se verifica que a economia de mercado não é um dado natural, mas que necessita de todo um quadro institucional para que funcione livremente. A questão institucional é, portanto, uma questão central para o pensamento neoliberal, sempre orientada pelo sentido da utilidade ao mercado. A reflexão de Foucault sobre o neoliberalismo será retomada ao longo do argumento desta pesquisa sobre as transformações do modo de intervenção estatal na vigilância sanitária. Pretende-se, na próxima seção, analisar como a resposta à questão do "como intervir" na economia no setor de vigilância sanitária é informada por demandas de um regime multilateral de comércio: para que a concorrência internacional funcione o mais livremente possível, uma institucionalidade com características específicas no campo da vigilância sanitária é necessária.

\section{A VIGILÂNCIA SANITÁRIA COMO BARREIRA COMERCIAL: O REGIME MULTILATERAL DE COMÉRCIO DEMANDA UMA INSTITUCIONALIDADE ESPECÍFICA}

A inserção do tema "saúde" na agenda do comércio internacional deuse em virtude da percepção da possibilidade de utilizá-la como justificativa para criar restrições à livre circulação de produtos, em um contexto em que as restrições quantitativas ao comércio de bens, como quotas e tarifas, são

(12) FOUCAULT, Michel, op. cit., p. 137, tradução livre.

(13) Id. loc. cit. 
gradualmente reduzidas. Isso acontece com a assinatura do Acordo Geral sobre Tarifas e Comércio (General Agreement on Tariffs and Trade - GATT), em 1947, um acordo multilateral pelo qual os países signatários se comprometeram a reduzir suas barreiras comerciais, por meio de rodadas de negociação. Assim, ao longo da segunda metade do século $X X$, a evolução do desgravamento tarifário põe em evidência outras formas de restrição ao comércio, entre as quais a regulamentação de produtos que oferecem risco à saúde humana ${ }^{(14)}$.

Há uma clara tensão neste momento, entre a saúde e o comércio internacional, pois os regulamentos e medidas estatais estabelecidos para proteger a saúde de suas populações criavam, muitas vezes, restrições à livre circulação de produtos e, sobretudo, distorções à concorrência perfeita. Isso porque não bastavam as baixas tarifas de importação, como resultado dos compromissos assumidos no âmbito do GATT, para que um produto estrangeiro estivesse em condições as mais próximas possíveis da concorrência perfeita com o produto nacional. Ele deveria, ademais de cumprir com os regulamentos de seu país de origem, também cumprir com os requisitos sanitários do país de destino, o que aumentava seus custos ou, muitas vezes, impedia sua entrada. Assim, se um país requer advertências específicas no rótulo de produtos saneantes, a apresentação de estudos clínicos de medicamentos realizados em seu território, a rotulagem nutricional em sua língua oficial, registro de um cosmético no seu órgão sanitário, o produto estrangeiro tem que atender a estas exigências para ser importado. Por vezes, há exigências que impedem a entrada de produtos, como frangos provenientes de regiões acometidas pela epidemia da influenza aviaria ou frutas que apresentam resíduos de pesticidas mais altos do que os considerados seguros no país de destino ou mesmo de pesticidas por ele não autorizados.

Se, por um lado, o objetivo destas medidas é considerado legítimo no âmbito do GATT, em seu artigo de exceções gerais, o artigo XX.b, por outro, há a preocupação de que elas possam ser utilizadas como pretexto para fins protecionistas, o que vai de encontro ao objetivo do regime multilateral de comércio, que é a liberalização comercial. Nesse sentido, em um momento de fortalecimento do regime multilateral do comércio - a criação da Organização Mundial do Comércio (OMC), em 1994 — os Estados-Membros assumem compromissos que disciplinam como elaborar e aplicar medidas que visam à proteção da saúde de suas populações de forma que estas não restrinjam o comércio mais do que o necessário para atingir aquele objetivo.

(14) No comércio internacional, o universo de produtos manufaturados submetidos a controles nãotarifários aumentou de menos de 1\%, em 1974, para cerca de $20 \%$ em 1985 (MILNER apud LUCCHESE, 2001, 28). No Brasil, a participação dos produtos sujeitos à vigilância sanitária no PIB é de $25 \%$ (ANVISA, 2004). 
Ressalte-se que o objetivo destas medidas não deixa de ser considerado legítimo, mesmo que elas impeçam a livre circulação de bens. Todavia, esta legitimidade está condicionada ao cumprimento de algumas obrigações assumidas nos Acordos da OMC.

Entre estes compromissos destacam-se, para os fins do presente estudo, aqueles assumidos no âmbito do Acordo sobre a Aplicação de Medidas Sanitárias e Fitossanitárias (mais conhecido por sua sigla em inglês por Acordo SPS/OMC ou apenas SPS) e do Acordo sobre Barreiras Técnicas ao Comércio (também conhecido pela sigla em inglês como Acordo TBT/OMC ou apenas TBT), contidos no anexo 1A da Ata Final da Rodada Uruguai, assinada em abril de 1994, em Marrakesh. O TBT tem impactos na vigilância sanitária, pois tem como escopo regulamentos técnicos e procedimentos de avaliação da conformidade, e a vigilância sanitária se exerce por meio da regulamentação, do monitoramento e da fiscalização do cumprimento dos regulamentos em produtos que oferecem riscos à saúde humana, como medicamentos, produtos biológicos (vacinas, órgãos, tecidos e derivados do sangue), produtos para saúde (equipamentos para diagnóstico, produtos odontológicos), cosméticos e produtos de higiene pessoal, saneantes, derivados do tabaco e alimentos. Já o escopo do Acordo SPS é mais limitado, sendo que sua definição de medida sanitária limita-se, dentre os produtos sujeitos à vigilância sanitária, aos que oferecem risco a partir do consumo de alimentos.

Tendo em vista que medidas sanitárias e fitossanitárias, tais como definidas na $\mathrm{OMC}$, são um tipo de regulamento técnico que se aplica à segurança dos alimentos, o escopo do SPS é mais específico do que o do TBT, tanto no que tange aos produtos que abarca - pois o TBT aplica-se a qualquer tipo de produto, de bicicletas a lâmpadas - , como aos objetivos da regulamentação - as medidas sanitárias e fitossanitárias objetivam à proteção da saúde humana, animal e vegetal, enquanto os objetivos considerados legítimos no Acordo TBT para regulamentos técnicos incluem a segurança nacional, a prevenção de práticas desleais, a proteção da saúde e segurança humana, vegetal e animal e do meio ambiente (art. 2.2). Assim, embora o SPS não abarque todos os produtos sujeitos à vigilância sanitária e inclua medidas que não visam à proteção da saúde humana, mas à saúde animal e vegetal, esta pesquisa restringe-se à análise ao Acordo SPS, pela necessidade de um recorte. Entretanto, são Acordos que estabelecem direitos e obrigações muito semelhantes, pois ambos partem dos princípios do regime multilateral de comércio.

Uma breve análise do Acordo SPS permite ressaltar as disciplinas centrais que ele estabelece aos Membros da OMC. Em primeiro lugar, ele prevê o direito dos Membros de aplicarem medidas para proteção da saúde, desde que cumpram as obrigações por ele previstas, vide art. 2.1. Cumprir o Acordo significa, dentre outros, basear suas ações em justificativas científicas suficientes (art. 2.2), por meio de uma avaliação de riscos (art. 5.1); caso 
não haja fundamentação científica suficiente, a adoção de uma medida deve ter caráter provisório e o Membro se obriga a buscar mais evidências e revisar sua medida (art. 5.7); estabelecer medidas que sejam o menos possível restritivas ao comércio (art. 5.6); adotar medidas consistentes (art. 5.5); basear suas medidas em referências internacionais, com vistas à harmonização internacional (art. 3.1); aceitar as medidas de outros Membros como equivalentes, quando comprovado (art. 4.1); aplicar o princípio da regionalização (art. 6); agir de forma transparente, notificando suas medidas, concedendo prazo para comentários de outros Membros, levando estes comentários em consideração e concedendo prazo para entrada em vigor de forma a permitir a adequação dos exportadores às novas regras (art. 7 e anexo B).

O Acordo SPS determina, em seu Anexo A, quais são as organizações internacionais consideradas como referência a ser seguida pelos Membros em matéria de segurança dos alimentos (Codex Alimentarius), saúde animal (OIE) e saúde dos vegetais (CIPV). Assim, o sistema multilateral de comércio remete a outros regimes internacionais em razão da especificidade da base técnico-científica requerida para justificar as medidas sanitárias. Estas organizações são foros técnicos internacionais de harmonização de padrões. No entanto, os Membros têm direito de determinar seu nível adequado de proteção e, para tanto, adotar medidas mais restritivas do que os padrões internacionais. Mas, esta flexibilidade está condicionada a vários requisitos: que as medidas adotadas não sejam mais restritivas ao comércio do que o necessário para atingir o nível considerado adequado (art. 5.6) e que tenham fundamentação científica com base em uma avaliação de risco (art. 3.3), ou seja, que não sejam inconsistentes com as demais provisões do Acordo, especialmente os arts. 2.2 e 5.1 .

Como em todos os demais acordos da OMC, o não cumprimento destas obrigações pode ser questionado no órgão de solução de controvérsias da organização (art. 11). Quando um Membro é acusado de descumprir o Acordo SPS, cabe a ele o ônus da prova, ou seja, comprovar cientificamente que sua medida visa à proteção da saúde e respeita as obrigações acima arroladas. Se o art. 5.7 permite um grau de flexibilidade ao permitir a adoção de uma medida quando não há evidências científicas suficientes, sua aplicação é de tal forma disciplinada que demonstra que o regime multilateral de comércio não deixou espaço para a ação estatal sem alguma justificativa científica. A fundamentação pode ser insuficiente, mas, não inexistente. $\mathrm{O}$ artigo condiciona esse direito dos Membros à obrigação de buscar novas informações e, com base nelas, revisar a medida dentro de um período razoável de tempo. A jurisdição da OMC reforçou esta interpretação, não acolhendo a defesa baseada neste artigo, se todos estes requisitos não forem cumpridos ${ }^{(15)}$.

(15) LIMA, Rodrigo C. de A. Medidas sanitárias e fitossanitárias na OMC: neoprotecionismo ou defesa de objetos legítimos. São Paulo: Aduaneiras, 2004. 
Ressalte-se que o objetivo principal da solução de controvérsias é fazer com que o Membro se adeque às regras do regime multilateral de comércio, fim para o qual a aplicação de sanções, como retaliações comerciais, são um meio. A adequação da medida às regras do regime é sua adequação à verdade, ao que é certo, ao passo que manter a medida e não acatar as recomendações do órgão de solução de controvérsias da OMC é insistir no erro. O mercado internacional passa a ser, na linha de Foucault, o lócus de veridição da prática governamental em matéria de vigilância sanitária.

O maior comprometimento dos países com o livre comércio, a partir da criação de uma organização internacional com poderes de solucionar controvérsias e autorizar sanções, incluiu, dentre suas implicações, que os países estavam subsumindo ao regime multilateral de comércio parte de sua soberania sanitária, com a assinatura de um Acordo como o SPS. Se o mercado internacional passa a ser o local de veridição da atuação do Estado em vigilância sanitária, pode-se prever que há uma mitigação progressiva das racionalidades próprias aos campos da saúde e do comércio internacional, pois aquele se torna parte deste, ao menos parcialmente. A partir do momento em que foi aberto esse espaço para a saúde no âmbito do regime multilateral de comércio, é este que define se a prática governamental em vigilância sanitária é boa ou ruim, quando ela ameaça o livre comércio internacional.

Ao contrário do que alguns argumentam, de que o Acordo SPS seria um paradoxo na OMC, ao legitimar a aplicação de barreiras ao comércio(16), trata-se de um fortalecimento do mercado internacional sobre a soberania sanitária dos países, já que sua ação fica disciplinada pela OMC. O Acordo SPS não legitima barreiras ao comércio; o que ele faz é estabelecer uma vigilância constante sobre as alegações sanitárias de medidas que podem restringir o comércio. Desta forma, ele representa o poder do mercado em definir o limite da ação estatal em matéria sanitária, estabelecendo os critérios de sua legitimidade. A vigilância sanitária passa a ser julgada a partir do ponto de vista do regime multilateral de comércio, como uma exceção à regra do livre comércio, cuja validade está condicionada ao cumprimento das regras da OMC.

A OMC passa a questionar a utilidade da ação estatal na vigilância sanitária, definindo seus limites - o limite entre a necessidade de proteger a saúde e os efeitos negativos para o comércio, informando que a opção sempre deve ser feita pela medida menos restritiva possível ao comércio. A pergunta utilitarista é constantemente feita: "isso é útil, a quem isso é útil, dentro de que limites isso é útil, a partir do que isso se torna inútil, a partir de que isso se torna nocivo?"(17) (FOUCAULT, 2004, p. 42, tradução livre). A medida pode restringir o comércio no limite do necessário para proteger a saúde e

(16) LIMA, Rodrigo C. de A., op. cit., p. 20-21.

(17) FOUCAULT, Michel. op. cit., p. 46, tradução livre. 
não mais do que isso. Esta definição é orientada por um cálculo de custobenefício; os benefícios para a saúde de uma medida estão agora sempre definidos de forma relativa, ou seja, com relação ao seu custo para o comércio (art. 5.3). A prática governamental em vigilância sanitária se opera, portanto, entre o limite da utilidade para o mercado e da necessidade de consolidar o direito à saúde. Para estabelecer a utilidade de suas ações, o Estado se vê, retomando Foucault, em um jogo complexo de interesses, "[...] entre os interesses individuais e coletivos, a utilidade social e o lucro econômico, entre o regime do poder público e o equilíbrio de mercado." O equilíbrio destes interesses é orientado, quando não julgado, pela OMC.

Esta disciplina estabelecida pela OMC sobre a prática governamental no campo da vigilância sanitária visa garantir a segurança e a previsibilidade para o comércio internacional, pois "[...] a ameaça de uma medida que venha a barrar as importações de determinado produto transgênico, ou, ainda, a existência de uma medida já imposta, envolvem, além de valores significativos, a quebra de expectativa e segurança dos contratos comerciais celebrados"(18). Trata-se um ponto fundamental para o neoliberalismo, a necessidade de intervir nos processos externos ao mercado que podem perturbar a livre concorrência, como argumentado na seção anterior.

Se é possível concluir que o regime multilateral de comércio criou certa convergência de expectativas dos atores, estabelecendo constrangimentos ao que poderia ser denominado, até então, "soberania sanitária" dos países, há de se ressaltar que as regras jurídicas que ele estabelece e a ciência que é utilizada como critério de legitimidade não existem em um vácuo, mas operam em um contexto internacional caracterizado por assimetrias entre os Membros da OMC. Essa assimetria se traduz em diferentes graus desta soberania sanitária, sendo que alguns países são mais capazes de cumprir as regras da $\mathrm{OMC}$ e que outros, não só têm dificuldades em cumpri-las, para garantir a segurança de suas populações, como também têm problemas em atender aos requisitos para exportar seus produtos.

Como pudemos observar nos acordos sanitários do GATT, constituintes da Organização Mundial do Comércio, os países centrais, importantes reguladores do mercado mundial, podem definir um padrão alto de exigência aos produtos que importam de outros países. Basta justificarem cientificamente que suas exigências são necessárias para a segurança e proteção sanitária de sua população, o que não é nada difícil em face de seus recursos institucionais de pesquisas e desenvolvimento e de expertise nos mais variados campos $^{(19)}$.

(18) LIMA, Rodrigo C. de A., op. cit., p. 262.

(19) LUCCHESE, Geraldo. Globalização e regulação sanitária: os rumos da vigilância sanitária no Brasil. 2001. Tese - (Doutorado) - Escola Nacional de Saúde Pública da Fundação Oswaldo Cruz, Rio de Janeiro, 2001. p. 216. 
Esta discricionariedade com respeito ao nível de proteção considerado adequado para a sua população não está disponível de forma igualitária em um sistema internacional assimétrico em termos econômicos, políticos e de conhecimento. Cumprir as regras deste regime para ser ator da competição comercial internacional requer recursos humanos, financeiros e tecnológicos, ou seja, condições institucionais como o financiamento e a capacidade técnico-científica para fundamentar as medidas sanitárias, tendo em vista os altos custos de se realizar uma análise de risco completa, bem como pessoal qualificado com conhecimento dos instrumentos jurídicos internacionais para cumprir as obrigações de transparência. Segundo Lucchese ${ }^{(20)}$, "não basta ter razão, estar moral e juridicamente correto; é preciso ter uma institucionalidade mínima para poder mostrar e impor essa razão".

O próprio Acordo SPS prevê, entre seus dispositivos, a assistência técnica em termos de tecnologias, pesquisa, infra-estrutura "e, inclusive, no estabelecimento de órgãos regulatórios nacionais” (art. 9.1, grifo nosso) para assegurar que países em desenvolvimento possam cumprir os requisitos sanitários dos países importadores ${ }^{(21)}$. identifica três frentes do desafio que os países em desenvolvimento enfrentam: a participação na OMC (nas reuniões que ocorrem em Genebra, o que implica, além de pessoal qualificado, custos de deslocamento ou de manutenção de representações diplomáticas); a participação nos foros técnicos internacionais de referência para a OMC (Codex, OIE e CIPV); a estrutura interna para implementar as regras da OMC.

Ao lado do art. 9, que trata da assistência técnica, o art. 10, que prevê concessão por parte dos países desenvolvidos de tratamento especial e diferenciado aos países em desenvolvimento, como prazos maiores para adequação às suas exigências, são temas constantes da agenda do Comitê SPS, o Comitê responsável pela administração do Acordo. Também no sentido de garantir a institucionalidade mínima dos países menos desenvolvidos para cumprir suas obrigações nestes Acordos foi criado um fundo de financiamento de projetos ${ }^{(22)}$. Não cabe aqui fazer uma avaliação dos resultados destas iniciativas, mas, apenas, alertar para o fato de que sua existência, por si só, é indicativa da demanda que o funcionamento do livre mercado cria por um marco institucional forte, que seja o mais apto possível a garantir que aspectos tão-somente técnicos fundamentem as medidas que possam afetar o comércio, isolando motivações políticas como o protecionismo. Trata-se da busca de uma resposta ao problema do neoliberalismo que Foucault formula nos seguintes termos: "[...] como se pode regular o exercício global do poder político de acordo com os princípios de uma economia de mercado"(23), tradu-

(20) LUCCHESE, Geraldo, op. cit., p. 215.

(21) LIMA, Rodrigo C. de A., op. cit., p. 282.

(22) Standards and Trade Development Facility (OMC, 2003).

(23) FOUCAULT, Michel, op. cit., p. 137. 
ção livre), partindo da constatação da dissociação entre o princípio econômico do mercado e o princípio político do laissez-faire e, conseqüentemente, da identificação da necessidade de uma intervenção estatal para garantir um quadro institucional que vigie possíveis interferências no mercado, como as medidas de vigilância sanitária, neste caso.

Contrariando uma tendência vigente nos países em desenvolvimento e, principalmente, nos países de menor desenvolvimento relativo, a da "renúncia de prerrogativas", no sentido de seguir as regulamentações sanitárias adotadas pelos países desenvolvidos, e, concomitantemente, perpetuar a assimetria no sistema internacional do controle sanitário, "[...] felizmente, nos últimos anos, o governo brasileiro definiu-se por investir na plena capacitação de sua capacidade regulatória"(24). A Reforma do Estado no Brasil, contemplando uma estrutura de agência reguladora para a vigilância sanitária vai ao encontro destas demandas do regime multilateral de comércio e do ideário neoliberal que lhe orienta.

\section{UMA AGÊNCIA REGULADORA EM VIGILÂNCIA SANITÁRIA?}

A reflexão sobre o papel do Estado na qual se baseou a Reforma do Estado no Brasil na década de noventa envolveu, na linguagem de Foucault, as questões "em que intervir" e "como intervir"? No Plano Diretor da Reforma do Aparelho do Estado(25), apresentado pelo então Ministério da Administração Federal e Reforma do Estado (MARE), a resposta à primeira questão passou pela decisão sobre os limites desejáveis da atuação do Estado, tendo sido decidido que a produção para o mercado era uma atuação "demasiada", devendo sair do âmbito estatal. Assim, um dos componentes da Reforma do Estado brasileiro foi a privatização, a retirada da intervenção direta do Estado na atividade econômica como provedor de serviços e produtos.

As privatizações no Brasil ocorreram nos setores de infra-estrutura, nos quais o Estado havia mantido forte presença direta, como energia elétrica, petróleo, gás natural, telecomunicações, água e saneamento. Por mais que o Estado se retirasse da atividade direta na economia, deixando o livre mercado atuar nestes setores, haveria outros motivos para que o Estado tivesse algum tipo de intervenção. Do ponto de vista neoliberal, a principal justificativa para uma intervenção estatal seria a tendência ao monopólio dos setores de infra-estrutura, a qual impede que estes mercados se constituam como lócus de veridição, o lugar onde mecanismos naturais e espontâneos formam um preço natural, revelando uma verdade. Isso porque as caracterís-

(24) LUCCHESE, Geraldo, op. cit., p. 268.

(25) BRASIL. Ministério da Saúde. Agência Nacional de Vigilância Sanitária. À sua saúde: a vigilância sanitária na história do Brasil/Eduardo Bueno. Brasília: Ministério da Saúde: Agência Nacional de Vigilância Sanitária, 2005. 
ticas de monopólio distanciam estes setores da concorrência perfeita. A identificação da existência de falhas nestes mercados remeteu à definição entre intervir e não intervir para a questão neoliberal do "como intervir" de forma a garantir um quadro institucional para o funcionamento da economia de mercado.

A Reforma do Estado brasileiro foi buscar nos Estados Unidos o modelo institucional que vinha sendo utilizado naquele país, desde o fim do século XIX, para estabelecer em mercados monopolísticos condições que mais os aproximassem de um mercado de concorrência perfeita. $O$ modelo de agências reguladoras foi uma tentativa de resposta à segunda questão foucaultiana, na medida em que foi considerado pelos proponentes da Reforma do Estado no Brasil o mais adequado para garantir a eficácia dos mercados de infraestrutura. Um dos motivos seria a própria definição de "regulação" encontrada na literatura acadêmica norte-americana, que influenciou a significação do termo no Brasil: regulação econômica é a correção de falhas do mercado ${ }^{(26)}$ Segundo Salgado(27), a intervenção estatal denominada "regulação" visa, justamente, garantir a concorrência via regulação de condições de entrada e de saída, de preços e de qualidade. Posner ${ }^{28)}$ define regulação de forma mais ampla, como "o padrão da intervenção estatal no mercado".

Assim, o órgão estatal cuja finalidade é a regulação de mercado dispõe de uma gama de poderes, que podem ser assim classificados, segundo Marques $^{(29)}$ :

1) competência normativa derivada: regulamentar, isto é, expedir regulamentos, nos limites autorizados pela lei;

2) poder de outorga: adjudicar ou interditar o exercício da atividade regulada via autorização, licença, registro e outros instrumentos;

3) fiscalização: monitorar para obtenção de informações sobre o setor e verificar se os entes regulados estão atuando de acordo com as regras para o setor;

4) sancionatório: uma vez verificada prática em desacordo, aplicar sanções (advertências, multas, cassações de licenças, obrigação de reparar um consumidor ou corrigir efeitos lesivos de sua conduta);

5) conciliação: dirimir conflitos entre regulados, especialmente no setor de infra-estrutura;

6) recomendação: subsidiar a formulação de políticas públicas.

(26) MATTOS, Paulo Todescan Lessa (Coord.). Regulação econômica e democracia: o debate norteamericano. São Paulo: Ed. 34, 2004; SALGADO, Lúcia Helena. Agências regulatórias na experiência brasileira: um panorama do atual desenho institucional. Rio de Janeiro: IPEA, 2003. 52 p. (Texto para discussão n. 941).

(27) SALGADO, Lúcia Helena, op. cit., p. 2-3.

(28) 1974 in MATTOS, Paulo Todescan Lessa (Coord.), op. cit.

(29) MARQUES NETO, Floriano de Azevedo, op. cit., p. 60-61. 
Tal amplitude de poderes leva às características necessárias para exercê-los, as quais também inspiraram a adoção do modelo de agências reguladoras no Brasil. Assim, a regulação de mercado distingue-se pela setorialidade, pelo alto grau de especialização técnica e pela independência decisória. $\mathrm{O}$ alto grau de conhecimento sobre o funcionamento de um setor de mercado de modo a conhecer suas leis e prever o comportamento dos atores é condição para que a intervenção estatal no mesmo tome a forma que mais se aproxime do que aconteceria se houvesse as leis da concorrência atuando livremente, o que também pressupõe a independência de fatores externos ao mercado, como a política.

Marques $^{(30)}$ salienta que a capacitação técnica, obtida tanto no momento do recrutamento dos seus funcionários como no incentivo ao seu desenvolvimento, é fundamental às agências devido à especificidade do setor regulado e à conseqüente necessidade de que a regulação a ele se adapte. Segundo o autor, a especificidade e, sobretudo, o dinamismo de muitos setores reforçam a importância de uma constante capacitação técnica, no intuito de diminuir a assimetria de conhecimentos entre o regulador e o regulado.

No que diz respeito à independência decisória, trata-se de um elemento que tomou relevância maior após severas críticas que a experiência das agências reguladoras nos Estados Unidos suscitou e que poderiam ser resumidas no dogma de que se há uma política, no sentido de intervenção estatal, que pretende "vigiar" o mercado, garantindo um quadro institucional para o funcionamento mais próximo possível da concorrência pura, esta intervenção estatal deve se dar nos moldes da economia e tão-somente nestes, afastando toda e qualquer influência de fatores políticos - políticos no sentido do poder de grupos de interesse em obter uma intervenção estatal a seu favor. As denúncias e os estudos de captura suscitaram, desta forma, a reflexão sobre o desenho institucional das agências que melhor insularia suas decisões de interferências políticas. Assim, entre as características institucionais que as agências reguladoras deveriam ter, foram defendidas: a criação de mandatos fixos de dirigentes, não coincidentes, e remoção apenas em casos limitados e previstos, a independência financeira; a criação de comissões colegiadas para impedir corrupção, a realização de audiências públicas e gravadas para a comunicação com o setor regulado e a sociedade.

Marques $^{(31)}$ afirma que a independência das agências baseia-se em dois pilares: a orgânica e a funcional. A primeira refere-se à incolumidade decisória, ou seja, a blindagem do regulador contra ingerências do poder central quando da sua atividade decisória. Ela é instrumentalizada da se-

(30) MARQUES NETO, Floriano de Azevedo, op. cit.

(31) Id. Ibid. 
guinte forma: um processo complexo de escolha do dirigente, que parte do Poder Executivo, passa pela sabatina do Legislativo e requer a nomeação do Chefe do Executivo; a investidura no cargo de dirigente por prazo determinado, isto é, por mandatos fixos; a não subordinação hierárquica, que se traduz na inexistência de poder revisório. A independência funcional ou administrativa é a previsão de instrumentos administrativos para que a independência se afirme, tais como: fontes próprias de receita (como as taxas do poder de polícia que custeiam as atividades das agências); quadro próprio de pessoal dentro de carreira específica para regulação (o que requer capacidade técnica específica); possibilidade de definir orçamento e prioridades para manejo de suas competências; autonomia para organizar seus serviços.

A criação deste modelo de órgão para regulação de mercado significa, portanto, que: 1) se assume o pressuposto neoliberal de que o Estado deve intervir na economia para regular mercados, tendo em vista que estes necessitam de um quadro institucional para funcionarem o mais próximo possível da concorrência perfeita; 2) ao mesmo tempo que se assume este papel regulador do Estado, são estabelecidos os limites desejáveis de sua atuação, definindo-se que as agências reguladoras são órgãos de Estado e não de governo e, para tanto, adotando-se um desenho institucional o mais blindado possível de mudanças políticas.

A independência política e financeira, bem como a justiça procedimental, passam a ser características institucionais típicas das agências reguladoras, de forma a garantir que ela exercerá suas competências o mais insuladamente possível de fatores externos à racionalidade do mercado, por meio de um processo que comprove e documente sua tomada de decisão como justa, isto é, aquela que reflete o interesse público, não tendo sido objeto de captura por interesses especiais. Juntamente com a setorialidade e a especialização técnica, estas foram as características institucionais que motivaram a inspiração no modelo norte-americano de agências reguladoras quando da resposta à pergunta do "como intervir" no desempenho de atividades exclusivas de Estado na Reforma do Estado brasileiro.

Segundo o Plano Diretor, a forma de administração a ser adotada nestas atividades deveria ser a "gerencial". Tratava-se da transformação da administração pública burocrática (rígida, ineficiente, voltada para si própria e para o controle interno) na administração pública gerencial (eficiente, flexível e voltada para o cidadão). A reforma gerencial da administração pública da década de noventa seria a forma que tomou no Brasil o que Foucault(32) chamou de o "Estado-empresa": "É essa multiplicação da forma 'empresa'

(32) FOUCAULT, Michel, op. cit., p. 154, tradução livre. 
no interior do corpo social que constitui, creio, o cerne do que está em jogo na política neoliberal. Trata-se de tornar o mercado, a concorrência e, por conseqüência, a empresa no que nos poderíamos chamar de potência informadora da sociedade".

A administração pública gerencial será aquela que, à maneira de uma empresa, é avaliada por sua eficiência. Se o interesse público é melhor traduzido pela alocação de recursos que só a concorrência pura é capaz de estabelecer, a busca pelo interesse público na prática governamental será pautada pela busca da eficiência dos mercados. A adoção do modelo das agências reguladoras em resposta à questão do "como intervir" baseia-se em suas características institucionais que mais se aproximam da flexibilidade gerencial para uma administração eficiente de mercados ineficientes.

Assim, de 1996 a 2005, foram criadas no Brasil dez agências reguladoras, cronologicamente: Agência Nacional de Energia Elétrica, Agência Nacional de Telecomunicações, Agência Nacional do Petróleo, Gás Natural e Biocombustíveis, Agência Nacional de Vigilância Sanitária, Agência Nacional de Saúde, Agência Nacional de Águas, Agência Nacional de Transportes Aquaviários, Agência Nacional de Transportes Terrestres, Agência Nacional do Cinema, Agência Nacional de Aviação Civil. Com base na análise de Foucault(33) $^{(3 a ̃ o}$ se trata de uma interpretação do senso comum a identificação da criação da Anvisa com o ideário neoliberal, pois este prevê um Estado forte regulador - e aí está uma das convergências entre saúde e comércio internacional. O refinamento da interpretação sobre o papel do Estado para o neoliberalismo por meio da leitura de Foucault permitiu a identificação desta relação em outros termos: de como demandas por uma maior institucionalidade sanitária convergiram para a adoção do modelo de agência reguladora dotado de maior capacidade de ação.

O discurso sobre um ambiente de estabilidade institucional que se pretendeu estabelecer com a criação da Anvisa, quando do debate sobre a Reforma do Estado brasileiro no setor de vigilância sanitária, incorpora, portanto, os pressupostos neoliberais sobre a relação entre Estado e mercado. A constatação da existência de falhas de mercado nos setores sujeitos à vigilância sanitária levou à percepção da necessidade de uma intervenção estatal permanente - nas palavras de Foucault, de uma "vigilância"; nos termos da teoria econômica da regulação, de uma "regulação econômica estatal" - o que, no contexto da Reforma do Estado assumiu a forma de uma agência reguladora. Este desenho institucional, com suas características de setorialidade, especialização técnica e independência incorporou também as demandas do regime multilateral de comércio, de que a livre concorrência só seja perturbada em virtude da proteção à saúde se fundamentada técnicocientificamente, sem a interferência de considerações políticas como o protecionismo de produtores nacionais disfarçado de medida sanitária.

(33) FOUCAULT, Michel, op. cit. 
A regulação estatal do risco sanitário sofre a dupla exigência do mercado de corrigir suas falhas e de que isso seja feito no limite exato da necessidade de proteção à saúde, restringindo o menos possível o livre comércio. Sua utilidade é delimitada pela capacidade do Estado em agir como uma empresa, pautado pelo critério da eficiência técnica e livre de considerações políticas.

\section{CONSIDERAÇÕES FINAIS}

Esta pesquisa partiu da problemática mais ampla das relações entre saúde e comércio internacional para analisar como a Reforma do Estado brasileiro em vigilância sanitária na década de noventa, notadamente, a criação da Anvisa está relacionada com o avanço do regime multilateral do comércio. A análise efetuada trouxe alguns apontamentos sobre a problemática geral da qual se partiu, dentre os quais se destaca a conclusão pela mitigação da autonomia da saúde frente ao regime multilateral de comércio.

A base teórica que sustentou a argumentação foi buscada na reflexão foucaultiana sobre a concepção neoliberal da intervenção estatal na economia. Procuramos analisar como as questões neoliberais de como (o quadro institucional necessário para que a livre concorrência possa atuar) e até que limite é útil a intervenção estatal na economia (a pergunta utilitarista) informaram as demandas tanto do mercado internacional como do mercado doméstico sobre as características do desenho institucional a ser adotado na Reforma do Estado em vigilância sanitária no Brasil.

Do ponto de vista do mercado internacional, se a inserção da saúde no regime multilateral de comércio se deu porque era percebida como barreira à livre concorrência (e, portanto, ao estabelecimento da verdade que só o funcionamento do livre mercado é capaz de traduzir), ela passou a ser disciplinada pelas regras daquele regime e sua autonomia frente a ele foi sendo progressivamente mitigada. Isto teve reflexos, inclusive, sobre a organização institucional da intervenção estatal em vigilância sanitária nos Membros da OMC. Assim, as obrigações assumidas no âmbito daquela organização para que o comércio e a concorrência internacionais funcionassem o mais livremente possível gerou demandas sobre um tipo de institucionalidade específico capaz de cumpri-las. As autoridades responsáveis pela regulação do risco sanitário passam a se orientar pelas idéias da fundamentação de suas ações no conhecimento e do insulamento de pressões políticas.

Considerando o mercado doméstico, estas características também eram bem-vindas, tendo sido contempladas no modelo das agências reguladoras adotado na Reforma do Estado realizada na década de noventa no Brasil. A criação de uma agência reguladora no setor de vigilância sanitária pode ser fundamentada, como buscamos desenvolver, na esteira das justificativas 
econômicas da regulação estatal no setor de infra-estrutura: para a correção de falhas de mercado. Após discorrer sobre as falhas de mercado nos setores sujeitos à vigilância sanitária e sobre a natureza da regulação estatal do risco sanitário, a conclusão foi de que a criação da Anvisa, tendo sido informada por um ideário neoliberal, significou um enfraquecimento da tensão entre o Estado protetor da saúde e o mercado, embora e justamente, porque esta transformação tenha como contrapartida uma maior intervenção estatal na economia. Em outras palavras, este enfraquecimento se deu porque a Reforma do Estado brasileiro foi orientada para sua utilidade ao mercado.

A intervenção estatal para a regulação estatal do risco sanitário sofre, pelos argumentos expostos, a dupla exigência (internacional e doméstica) do mercado de 1) corrigir suas falhas e 2) que isso seja feito no limite exato da necessidade de proteção à saúde, restringindo o menos possível o livre comércio. Sua utilidade é delimitada pela capacidade do Estado em agir como uma empresa, pautado pelo critério da eficiência técnica e livre de considerações políticas.

Retomando Foucault, a economia passa a ser o regime de veridição da prática governamental e a intervenção estatal em vigilância sanitária não escapa a este critério neoliberal. A saúde passa a fazer parte do regime multilateral de comércio e a Reforma do Estado em vigilância sanitária é influenciada por este processo. Assim, a transformação no modo de atuação estatal no setor foi informada pela utilidade para o mercado, doméstico e internacional, e o mercado demandou uma institucionalidade mais forte, uma maior intervenção na economia. Afirmar isto não é questionar os possíveis ganhos da criação da Anvisa para a consolidação do direito à saúde, pois estes ganhos não foram objeto de análise nesta pesquisa - constituindo, em nossa opinião, uma linha de pesquisa empírica que deveria ser desenvolvida. Esperamos que esta pesquisa possa contribuir para o debate sobre a Reforma do Estado em vigilância sanitária questionando o sentido deste ganho institucional regulatório, levantando o argumento de sua utilidade para o mercado, notadamente, o mercado internacional.

\section{REFERÊNCIAS BIBLIOGRÁFICAS}

AGÊNCIA NACIONAL DE VIGILÂNCIA SANITÁRIA (Anvisa). Boletim informativo, n. 42, abril de 2004.

BRASIL. Ministério da Saúde. Agência Nacional de Vigilância Sanitária, À sua saúde: a vigilância sanitária na história do Brasil/Eduardo Bueno. Brasília: Ministério da Saúde: Agência Nacional de Vigilância Sanitária. 2005.

Presidência da República. Análise e avaliação do papel das agências reguladoras no atual arranjo institucional brasileiro. Relatório do grupo de trabalho interministerial. Brasília, setembro de 2003. 
. Plano diretor da reforma do aparelho do Estado. Brasília: Câmara da Reforma do Estado da Presidência da República, 1995.

Lei n. 8.080, de 19 de setembro de 1990. Dispõe sobre as condições para a promoção, proteção e recuperação da saúde, a organização e o funcionamento dos serviços correspondentes, e dá outras providências. Diário Oficial da União, Poder Executivo, de 20 de setembro de 1990a.

CASTEL, Robert. A insegurança social: o que é ser protegido? Petrópolis: Vozes, 2005.

COSTA, Ediná Alves Costa; ROZENFELD, Suely. Constituição da Vigilância Sanitária no Brasil. In: ROZENFELD, Suely (Org.). Fundamentos da vigilância sanitária. Rio de Janeiro: Ed. FIOCRUZ, 2000. p. 15-40.

Vigilância sanitária: proteção e defesa da saúde. 2. ed. ampl. São Paulo: Sociedade Brasileira de Vigilancia de Medicamentos, 2004.

EUROPEAN FOOD SAFETY AUTHORITY (EFSA). Disponível em: <http:// www.efsa.europa.eu/en.html>. Acesso em: 27 fev. 2007.

GENERAL AGREEMENT ON TARIFFS AND TRADE (GATT). Disponível em: <http://www.wto.org/english/docs_e/legal_e/06-gatt_e.htm>. Acesso em: 6 dez. 2005.

GÓMEZ-IBAÑEZ, JOSÉ A. Regulating infrastructure: monopoly, contracts, and discretion. US: Havard University Press, 2006.

FOUCAULT, Michel. Naissance de la biopolitique. Cours au Collège de France. Ed. Seuil: Gallimard, 2004.

KRASNER, Stephen D. International regimes. Londres: Cornell Universty Press, 1983.

LIMA, Rodrigo C. de A. Medidas sanitárias e fitossanitárias na OMC: neoprotecionismo ou defesa de objetos legítimos. São Paulo: Aduaneiras, 2004.

LUCCHESE, Geraldo. Globalização e regulação sanitária: os rumos da vigilância sanitária no Brasil. 2001. Tese - (Doutorado) - Escola Nacional de Saúde Pública da Fundação Oswaldo Cruz, Rio de Janeiro, 2001.

MARQUES NETO, Floriano de Azevedo. Agências reguladoras independentes: fundamentos e seu regime jurídico. Belo Horizonte: Fórum, 2005.

MATTOS, Paulo Todescan Lessa (Coord.). Regulação econômica e democracia: o debate norte-americano. São Paulo: Ed. 34, 2004.

Regulação econômica e social e participação pública no Brasil. Paper submetido ao IX Congreso Internacional del CLAD sobre la Reforma del Estado y de la Administración Pública, Madrid, Espanha, 2 a 5 de novembro de 2004b. 22 p. Mimeo.

MINISTÉRIO DA SAÚDE. Portaria SVS/MS n. 85 de 6.8.93. 
NUNES, Edson. O quarto poder: gênese, contexto, perspectivas e controle das agências regulatórias. Paper submetido ao II Seminário Internacional sobre Agências Reguladoras de Serviços Públicos. Brasília: Instituto Hélio Brandão, 25 de setembro de 2001. 58 p. Mimeo.

ORGANIZAÇÃO DAS NAÇÕES UNIDAS PARA A ALIMENTAÇAO E A AGRICULTURA e ORGANIZAÇÃO MUNDIAL DA SAÚDE (FAO e OMS). Codex Alimentarius Commission: manual de procedimiento. 15. ed. Roma, 2005.

ORGANIZAÇÃO MUNDIAL DO COMÉRCIO (OMC) G/SPS/GEN/423. Operation of the Standards and Trade Development Facility. 27 de agosto de 2003.

Agreement on the application of sanitary and phytosanitary measures. Disponivel em: <http://www.wto.org/english/docs_e/legal_e/15sps_01_e.htm>. Acesso em: 6 dez. 2005.

Agreement on Technical Barriers to Trade. Disponivel em: <http:// www.wto.org/english/docs_e/legal_e/17-tbt_e.htm>. Acesso em: 6 dez. 2005.

PIOVESAN, Marcia Franke. A construção política da Agência Nacional de Vigilância Sanitária. Dissertação de Mestrado. Fundação Oswaldo Cruz. Escola Nacional de Saúde Publica. Rio de Janeiro: setembro de 2002.

RAMALHO, Pedro Ivo Sebba. A gramática política das agências reguladoras. Projeto de Tese apresentado ao Centro de Pesquisa e Pós-Graduação sobre as Américas. Brasília: Universidade de Brasília, junho de 2006. Mimeo.

ROZENFELD, Suely (Org.). Fundamentos da vigilância sanitária. Rio de Janeiro: Ed. FIOCRUZ, 2000.

SALGADO, Lúcia Helena. Agências regulatórias na experiência brasileira: um panorama do atual desenho institucional. Rio de Janeiro: IPEA, 2003. 52 p. (Texto para discussão n. 941)

WORLD TRADE ORGANIZATION/WORLD HEALTH ORGANIZATION (WTO/ WHO). WTO Agreements \& Public Health: a joint study by the WHO and the WTO Secretariat. 2002. 